\title{
Intussuscepção Intermitente de Lipoma de Cólon Transverso
}

\author{
Intermittent intussusception of transverse colon lipoma. Case report
}

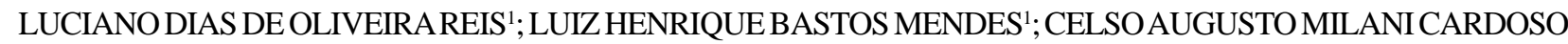 \\ FILHO $^{1}$; ADRIANO DIAS DE OLIVEIRAREIS ${ }^{1}$; JÚLIO DEASSIS MOREIRAARRUDA ${ }^{2}$ \\ ${ }^{1}$ Membros do departamento de cirurgia do Hospital Nossa Senhora da Saúde, Santo Antônio da Platina, Paraná; \\ ${ }^{2}$ Acadêmico da Faculdade de Medicina de São José do Rio Preto (FAMERP).
}

\begin{abstract}
REIS LDO; MENDES LHB; CARDOSO FILHO CAM; REIS ADO; ARRUDA JAM. Intussuscepção Intermitente de Lipoma de Cólon Transverso. Rev bras Coloproct, 2006;26(4): 447-448.

RESUMO: O lipoma colorretal é incomum. A maior parte das lesões são únicas, localizadas na submucosa, assintomáticas, sendo descoberta em autópsias ou em laparatomia por outras condições. Porém, em alguns casos são sintomáticos, e podem causar sangramento, obstrução intestinal, cólicas intestinais, prolapso e intussuscepção. Apresentamos um caso de lipoma submucoso de cólon transverso, cuja apresentação foi de intussuscepção intermitente. O lipoma foi ressecado através de uma colectomia segmentar e o paciente teve alta em bom estado geral.
\end{abstract}

Descritores: lipoma , lipoma colônico, pólipo.

\section{RELATO DO CASO}

O. S., prontuário 96028, masculino, 37 anos, branco, natural e procedente de Santo Antônio da Platina (PR), agricultor, internado com dor abdominal tipo cólica, em quadrante superior esquerdo do abdômen e flanco esquerdo, náusea, vômitos. A dor era intermitente. Suspeitou-se de cólica nefroureteral, porém ultrasonografia e exame parcial de urina foram normais. Paciente persistiu com sintomas, intermitentes e foi então solicitada uma colonoscopia que mostrou colite em sigmóide e lesão pediculada, com base larga, no colon transverso, recoberta com material fecal, retrátil, ocupando aproximadamente $70 \%$ da luz colônica (Figura 1). Tentativas de excisão foram infrutíferas e foram realizadas biópsias do pedículo da lesão. $\mathrm{Na}$ Laparotomia, encontramos colon tranverso com peristatismo intenso e com intussuscepção. Realizamos ordenha retrógrada e o colon voltou a sua posição original. Palpamos massa tumoral amolecida e decidimos realizar colotomia sobre a massa. Encontramos tumor com superfície homogênea, recoberta por fezes, com pedículo muito largo. Decidimos pela faci- lidade anatômica realizar uma colectomia transversa segmentar, com anastomose primária em dois planos, com acido poliglicólico. O resultado anatomopatológico foi de massa de $7 / 4 / 3 \mathrm{~cm}$, superfície levemente lobulada, granulosa, creme acastanhada, compatível com lipoma submucoso (Figura 2). Paciente evoluiu bem no pósoperatório, com fístula de baixo débito, que fechou rapidamente tendo o paciente alta no $9^{\circ}$ dia.

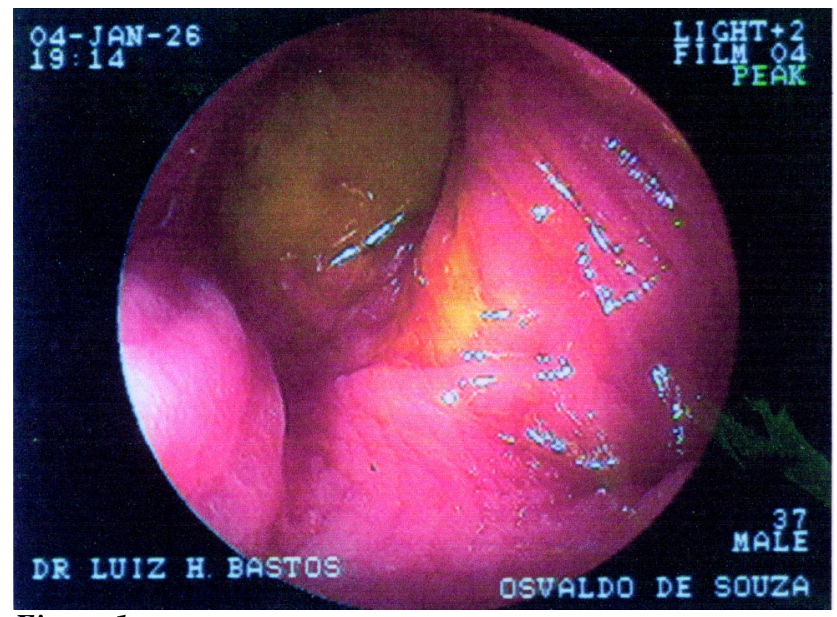

Figura 1

Trabalho realizado no Hospital Nossa Senhora da Saúde, Santo Antônio da Platina, Paraná.

$\overline{\text { Recebido em 29/07/2004 }}$

Aceito para publicação em 27/08/2004 


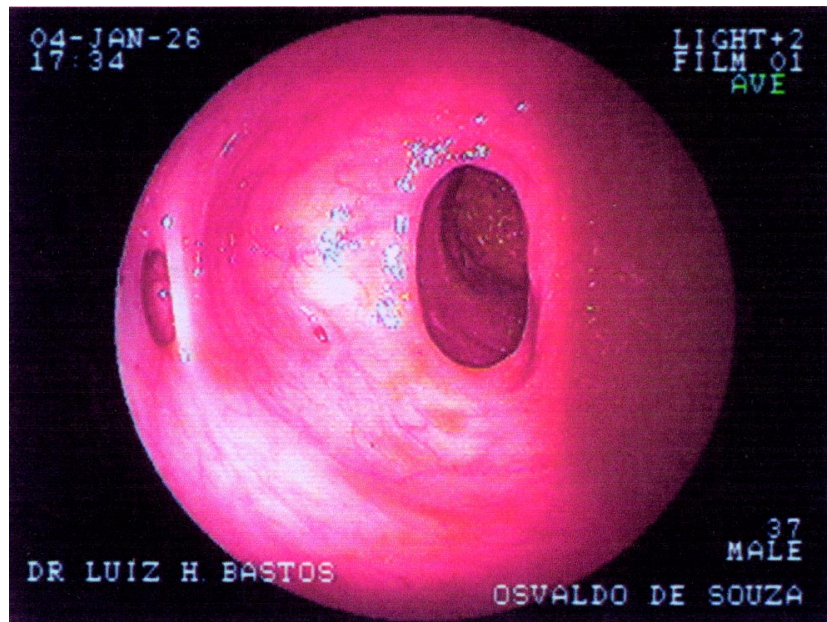

Figura 2

\section{DISCUSSÃO}

Os lipomas são tumores benignos que podem ocorrer em todo o trato intestinal e é mais comum no ceco e cólon direito. A maioria localiza-se no espaço submucoso, podendo acometer também o subseroso e os apêndices epiplóicos ${ }^{1,2}$. Sua incidência aumenta após os 50 anos e em aproximadamente $80 \%$ dos casos é único.
A maioria dos lipomas de cólon é assintomática, principalmente os de pequeno volume. Quando esses tumores são maiores que $4 \mathrm{~cm}$ de diâmetro, produzem sintomas em mais de $75 \%$ dos doentes, tais como: dor abdominal tipo cólica, mudança de hábito intestinal, massa palpável e perda de peso, dor abdominal vaga, sangramento pelo ânus ou anemia e menos frequientemente, sintomas e sinal de obstrução, ocasionados pelo próprio lipoma ou quando este apresenta como a "cabeça" de uma intussuscepção ${ }^{1,2,3}$. A intussuscepção é a complicação mais freqüente do lipoma submucoso ${ }^{1,3}$, como ocorreu no nosso caso. A intermitência dos sintomas provavelmente ocorreu devido a intussuscepções resolvidas expontaneamente por movimentos peristálticos reversos que ocorrem nos colons. Ocasionalmente a intussuscepção termina com prolapso do lipoma pelo ânus, quando e diagnóstico tornase evidente ${ }^{4,5,7,8}$.

Num período maior que duas décadas, 24 casos de intussuscepção colônica em adultos foram relatados na clínica Mayo, e destes apenas 2 eram devidos a lipoma do cólon ${ }^{1}$. O tratamento descrito na literatura inclui a ressecção do cólon por laparotomia ou laparoscopia bem como a remoção endoscópica do lipoma ${ }^{3,6}$.

ABSTRACT: Colo-rectal lipoma is uncommon. Most lesions are submucosal, single, assymptomatic , being discovered only on autopsy or at laparotomy for another condition, but sometimes it may cause change in bowel habit, bleeding, prolapse or intussusseption as in our case. The symptomatic lesions may be removed by colonoscopy, colotomy or colectomy. The authors report a case of a large lipoma in the transverse colon, submucosal, with intermittent intussusception, removed by laparotomy and segmental transverse colectomy. The patient made an uneventful recovery.

Key words: lipoma, colo-rectal lipoma, prolapsed polips, colonic intussusseption.

\section{REFERÊNCIAS}

1. Alponat A, Kok KYY, Goh PMY, Ngoy SS. Intermittent subacute intestinal obstruction due to a giant lipoma of the colon: a case report. Am Surg 1996; 62:918-921.

2. Catania G, Petralia GA, Migliore M, Cardi F. Diffuse coloni lipomatoses with giant hypertrophy of the epiploic appendices and diverticulosis of the colon. Dis Colon Rectum 1995; 38:769-775.

3. Cruz GMG, Oliveira AT, Rodrigues JVL. Lipomas colorretais: apresentação de 15 casos pessoais e revisão da literatura. Rev bras Coloproct 1997; 17: 32-41.

4. Albuquerque IC, Alves Filho EF, Paula Nunes BLBB, Nossa FLC, Barreto Neto PF, Silva JH \& Formiga GJS Intussuscepção colônica por lipoma. Relato de dois casos. Rev bras Coloproct 1998; 18(4): 256-259.
5. Lyra G, Coutinho RPCR; Leal RC. Lipoma Colônico Mimetizando Pólipo Gigante Parido - Relato de Caso. Rev bras Coloproct 2004; 24(1): 63-64.

6. Kim CY - Gastrointest Endosc-Endoscopic removal of large colonic lipomas. 01-Jun-2002; 55 ( 7 ) : 929-31.

7. Acceta I, Moraes FA, Duarte AM et al. Invaginação colocólica exteriorizada pelo ânus secundária a lipoma : relato de três casos .Ver.Bras. Colo-proctol, 1985, 5 ( 4 ) : 207-209.

8. Guerra GMLSR, Souza, HFS, Fonseca MFM et al. Intussuscepção colo-cólica esteriorizada pelo ânus, secundária a lipoma - Relato de Caso. Rev bras Coloproct, 2005; 25(4): 382-85.

Endereço para correspondência:

LUCIANO DIAS DE OLIVEIRA REIS

Rua 20 de Agosto, 111

86.430-000 - Santo Antônio da Platina (PR)

E-mail: reisluciano@uol.com.br 